\title{
High prevalence of cesarean section births in private sector health facilities- analysis of district level household survey-4 (DLHS-4) of India
}

Priyanka Singh ${ }^{1 *}$, Gulfam Hashmi ${ }^{2}$ and Prafulla Kumar Swain ${ }^{3}$

\begin{abstract}
Background: Worldwide rising cesarean section (CS) births is an issue of concern. In India, with increase in institutional deliveries there has also been an increase in cesarean section births. Aim of the study is to quantify the prevalence of cesarean section births in public and private health facility, and also to determine the factors associated with cesarean section births.

Methods: We analyzed data from district level household survey data 4 (DLHS-4) combined individual level dataset for 19 states/UTs of India comprising 24,398 deliveries resulting in 22,111 live births for year 2011. The percentages and Chi-square has been computed for the select variables viz. Socio demographic, maternal, antenatal care and delivery related based on type of births (CS Vs normal births). The multiple logistic regression model has been used to identify the potential risk factors associated with CS births.

Results: Of 22,111 live birth analyzed $49.2 \%$ were delivered at public sector, 31.9\% at private sector and 18.9\% were home deliveries. Prevalence of CS births were $13.7 \%(95 \% \mathrm{Cl} ; 13.0-14.3 \%)$ and $37.9 \%(95 \% \mathrm{Cl} ; 36.7-39.0 \%)$ in the public and private sectors, respectively. Higher odds of CS births were observed with- delivery at private health facility (OR 3.79; 95\% C.I 3.06-4.72), urban residence (OR 1.15; 95\% C.I 1.00- 1.35), first delivery after 35 years of maternal age (OR 5.5; 95\% C.I 1.85- 16.4), hypertension in pregnancy (OR 1.32; 95\% C.I 1.06- 1.65) and breach presentation (OR 2.37; 95\% C.I. 1.63- 3.43).

Conclusions: Our findings shows that CS births are nearly three times more in private as compared to public sector health facilities. The higher rates of CS births, especially in private sector, not only increase the cost of care but may pose unnecessary risks to women (when there is no indications for CS). The government of India need to take measures to strengthen existing public health facilities as well as ensure that cesarean sections are performed based upon medical indications in both public and private sector health facilities.
\end{abstract}

Keywords: Cesarean section, Normal delivery, Public sector, Private sector, Prevalence

\footnotetext{
* Correspondence: priyanka2614@gmail.com

${ }^{1}$ Nalanda Medical College, Patna, India

Full list of author information is available at the end of the article
}

(c) The Author(s). 2018 Open Access This article is distributed under the terms of the Creative Commons Attribution 4.0 International License (http://creativecommons.org/licenses/by/4.0/), which permits unrestricted use, distribution, and reproduction in any medium, provided you give appropriate credit to the original author(s) and the source, provide a link to the Creative Commons license, and indicate if changes were made. The Creative Commons Public Domain Dedication waiver (http://creativecommons.org/publicdomain/zero/1.0/) applies to the data made available in this article, unless otherwise stated. 


\section{Background}

Cesarean section (CS) when indicated is a live saving procedure but when performed without appropriate indications can add risk to both mother and baby [1] Globally there is an ongoing debate on what should be the optimal rates of CS deliveries [2-5]. As per recently published WHO report, "At population level, Cesarean section rates higher than $10 \%$ are not associated with reductions in maternal and new-born mortality rates" [1]. World-wide large disparity is observed in CS rates, highest rates being reported in Latin America and the Caribbean region (40.5), followed by Northern America (32.3), Oceania (31.1), Europe (25), Asia (19.2) and Africa (7.3) [6]. In India as per District level household survey 3 (DLHS) CS rate is $28.1 \%$ in private sector and $12 \%$ in public sector health facilities [7]. This survey shows share of Cesarean deliveries in institutional births have increased in India, especially in private sector health facilities. DLHS 4 also shows similar trend in various states though country wide reports are not currently available [8].

Researchers across world have come up with various reasons for rising CS rates, important ones being "patient's preferences", "fear of vaginal delivery" and "social norms" [9-11]. Different rates of CS births in public and private sector health facilities suggest that non-medical factors, such as financial gain, may motivate doctors to perform CS deliveries $[4,12]$.

There are lack of large recent population based studies from India to explore the determinants of CS births and influence of sociodemographic, maternal, pregnancy and delivery related factors on type of delivery (Normal/ Assisted versus Cesarean Section births).

The District Level Household Survey is one of the largest ever demographic and health surveys carried out in India, with a sample size of about seven lakh households covering all districts of the country $[7,8]$. The data from these surveys have been useful in setting the benchmarks and examining the progress the country has made after the implementation of reproductive child health $(\mathrm{RCH})$ programme. These surveys are useful for the central and state governments in evaluation, monitoring and planning strategies. In view of the completion of 6 years of National Rural Health Mission (2005-12), there is a felt need to focus on the achievements and improvements so far.

There is a paucity of information on Cesarean section rates based on analysis of India DLHS 4 individual level dataset. In present study we try to fill this gap and create evidence from DLHS-4 individual level dataset on factors associated with Cesarean section deliveries in India.

\section{Methods}

This study used data from District Level Household Survey (DLHS-4) individual dataset for all births of year 2011 (January 1 to 31st December) [8]. The Ministry of Health and Family Welfare (MoHFW), Government of India, conducted round 4 (DLHS-4) in 26 States and Union Territories of India during 2012-2013 (other than 9 states covered under Annual Health Survey, AHS). In the past, three rounds of DLHS have been undertaken (Round- I in 1998-99, Round-II in 2002-04, and Round-III in 2007-08). A multi-stage, stratified, probability proportional to size sample with replacement design was adopted by DLHS-4. Each district was divided into rural and urban areas. For rural areas primary sampling unit (PSU) was village and the Census of India 2001 was the sampling frame. For urban areas PSU were NSSO Urban Frame Survey (UFS) blocks. UFS blocks in each district have been stratified into million-class cities and non-million class cities and allocation of sample was proportional to relative sizes. Twenty-five households have been selected from each rural and urban PSU. Further detailed description of sample methodology and survey process of DLHS4 has been mentioned elsewhere [8] The survey obtained detailed information on socio demographic details, maternal characteristics, pregnancy and delivery from ever married woman aged 15-49 years.

As available in public domain (accessed from http:// www.iipsindia.ac.in/) at the time of analysis, combined individual data set for following 19 states/ UTs (Himachal Pradesh, Punjab, Haryana, Sikkim, Arunachal Pradesh, Nagaland, Manipur, Mizoram, Tripura, Meghalaya, West Bengal, Maharashtra, Andhra Pradesh, Karnataka, Goa, Kerala, Tamil Nadu and Telangana) were used for analysis in present study.

\section{Definition of variables \\ Outcome variable}

We defined the type of delivery (CS or normal) as outcome variable.

\section{Explanatory or independent variables}

A wide range of independent variables were used for this analysis. The potential select variables were: maternal age, place of residence, women's education, caste, age at first delivery, wealth index quartiles, received four or more ANC and abdomen checked, blood pressure measured, blood test for haemoglobin, urine test done at least once during pregnancy, Ultrasound done at least once during pregnancy, main place of receiving ANC, complications during pregnancy pallor/ weakness/ giddiness, weak or no movement of foetus, abnormal position of foetus, high blood pressure, bleeding during pregnancy and delivery complications prolonged labour, 
obstructed labour, excessive bleeding, breach presentation and convulsion and place of delivery place of delivery has been divided into public sector and private sector health facilities as categorised in DLHS questionnaire (refer Table 1).

Variables of interest were taken from "Ever Married Woman's Questionnaire”. The analysis is based on information regarding the latest birth of ever-married women aged 15-49 years, who had given live birth in year 2011 (1st January to 31st December) and reported the "type of delivery". Cesarean section rates were calculated as number cesarean section births out of total live birth for year 2011.

\section{Statistical analysis}

The proportion and percentages were computed and univariate Chi-square test was performed. A multiple logistic regression was used to determine the significant predictors associated with the CS births. Since the outcome variable is a dichotomous variable the multiple logistic regression model was a natural choice. The predictors which are found to be significant in univariate analysis are included in the regression model, the final model was adjusted for all the confounding variables. The results of the regression model have been presented in the form of odds ratio (OR) along with its 95\% confidence intervals (CI). The analysis accounted for complex cluster sampling design; hence a complex sample analysis was carried considering the study design and sampling weight of DLHS 4. All the statistical analysis was carried out using SPSS version-20.0. In all case the $P$-value $<0.05$ was considered as significant.

\section{Results}

\section{Type of delivery (refer Fig. 1)}

Of total 24,398 deliveries, 90.6\% $(N=22,111)$ were live births and rest $9.4 \%(N=2287)$ resulted in still births. $81.1 \%(N=17,934)$ of the total 22,111 live births were institutional (49.2 and $31.9 \%$ at public and private sector health facility respectively) and $18.9 \%(N=4177)$ delivered at home.

Prevalence of CS births were in public sector health facilities was13.7\% (95\% CI; 13.0-14.3\%) as compared to

Table 1 Subcategories for place of delivery in public and private sector health facilities

\begin{tabular}{ll}
\hline Place of delivery & Sub categories \\
\hline $\begin{array}{l}\text { Public sector } \\
\text { health facility }\end{array}$ & $\begin{array}{l}\text { Government/municipal hospital, government } \\
\text { dispensary, urban healthcare, urban family welfare } \\
\text { center, community health center, rural hospital, } \\
\text { primary health center, sub center, and village } \\
\text { clinic by auxiliary nurse midwife. }\end{array}$ \\
$\begin{array}{l}\text { Private sector } \\
\text { health facility }\end{array}$ & $\begin{array}{l}\text { Private hospital or clinic, and NGO } \\
\text { hospital or clinic. }\end{array}$ \\
Home & $\begin{array}{l}\text { Home, parent's home, work place, on way } \\
\text { to hospital, others }\end{array}$ \\
\hline
\end{tabular}

$37.9 \%$ (95\% CI; 36.7- 39.0\%) in private sectors health facilities.

\section{Socio demographic and maternal factors (refer Table 2)}

This study shows as the maternal age advances proportion of live births by cesarean section as compared to normal delivery increased from $18.5 \%$ in woman aged $<19$ years to $28.6 \%$ in age group $>35$ years $(p$ value $<0.001)$.

It was also observed that the CS births increases with advancing age of the women at the time of first delivery from $15.1 \%$ in aged less than 19 years to 53 . $2 \%$ amongst aged greater than 35 years $(P$ value $<0$. 001). Higher proportion of live birth deliveries in urban areas were through cesarean section (28.6\%) compared to $19.5 \%$ in rural areas, ( $p$ value $<0.001$ ). CS births were higher among women with any schooling (25\%) as compared to no schooling (12.6\%) ( $\mathrm{P}$ value $<0.001)$. SC/ST caste women reported less deliveries by $\mathrm{CS}$ as compared to other castes $(17.3 \%$ Vs 27\%).

Proportion of CS births significantly increased from lower to highest wealth index quartile $(p$ value $<0.001)$ $(13,19,26,4,30.2 \%$ in first, second, third, fourth quartile respectively).

\section{Pregnancy and delivery related factors (refer Table 3)}

It was observed that delivery by cesarean section was 26 . $9 \%$ in women who received 4 or more ANC and $18.0 \%$ in women who received less than 4 ANC ( $p$ value $<0.001)$.

Similar pattern was seen with those who received abdomen checkup, blood pressure checked, blood test for hemoglobin and urine test done at least once during pregnancy. Overall, it was observed that the CS births were $24.4 \%$ in women who received abdomen checkup, blood pressure checked, blood test for hemoglobin and urine tested at least once during pregnancy as compared $12.9 \%$ in women who did not receive these checkup even once during pregnancy ( $p$ value $<0.001)$.

Women who reported ultra sound at least once had $27 \%$ CS births compared to $14.6 \%$ in women who did not report ultra sound test ( $p$ value $<0.001)$.

$35.1 \%$ women receiving ANC primarily at private hospitals delivered by cesarean section compared to $16.7 \%$ women who received ANC primarily at public hospitals and $19.6 \%$ in women who received ANC at home.

Woman with high blood pressure during pregnancy had significantly higher proportion of $\mathrm{C} S$ births than those who had normal blood pressure $(35.1 \%$ Vs 22.6\%).Woman with delivery related complications of convulsion, prolonged labour and breach presentation had significantly higher proportions of CS births ( $p$ value $<0.001)$. 


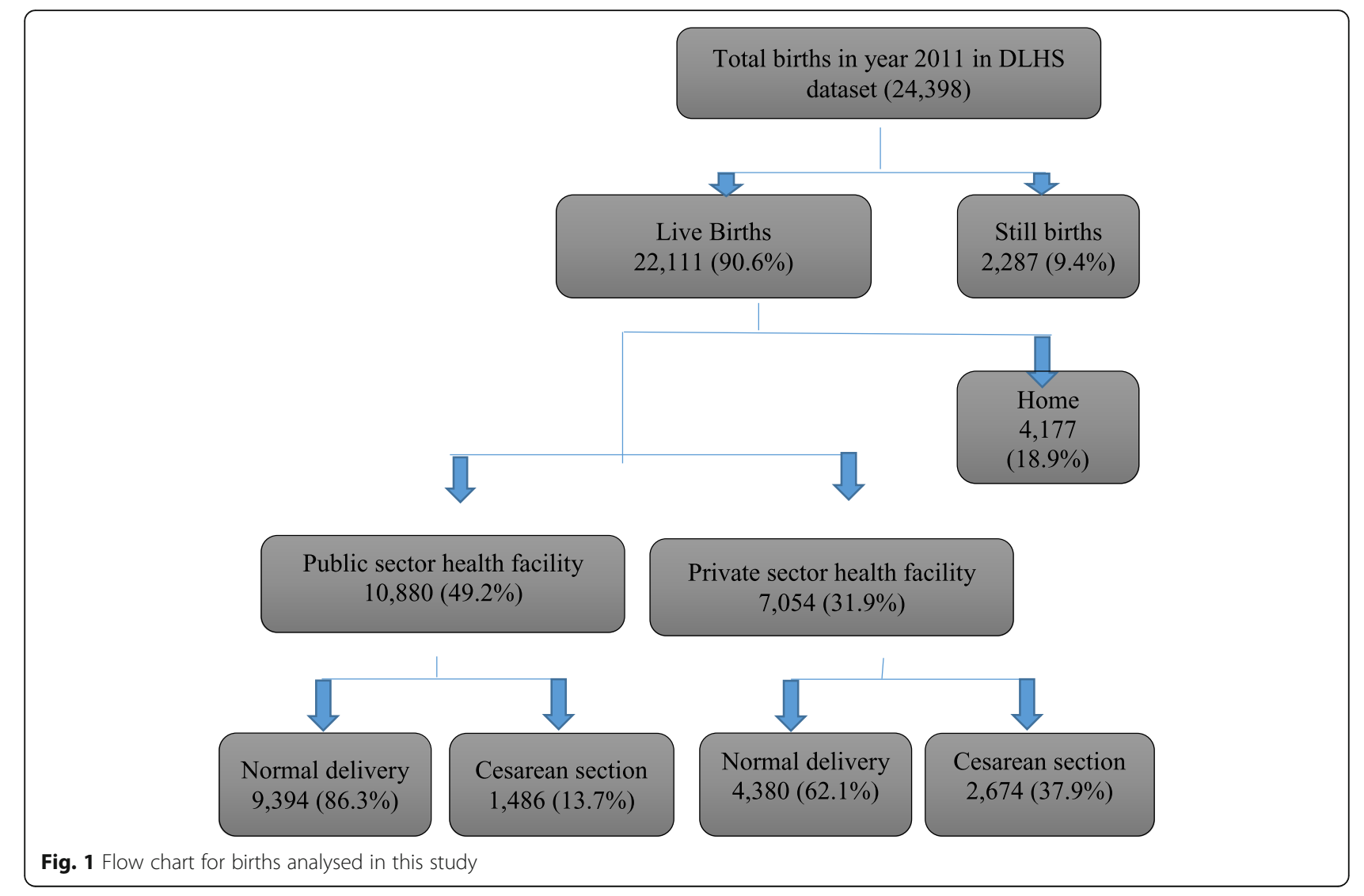

Table 2 Sociodemographic and maternal factors based on type of delivery

\begin{tabular}{|c|c|c|c|c|c|}
\hline \multirow[t]{2}{*}{ Variables } & \multirow[t]{2}{*}{ Categories } & \multirow{2}{*}{$\begin{array}{l}\text { Normal } \\
\text { N (\%) }\end{array}$} & Caesarean Section & \multirow[t]{2}{*}{ Chi-Square } & \multirow[t]{2}{*}{$P$-Value } \\
\hline & & & N (\%) & & \\
\hline \multirow[t]{4}{*}{ Age of Mother } & $<=19$ Years & $330(81.5)$ & 75 (18.5) & 80.62 & 0.001 \\
\hline & 20 - 24 Years & $4874(80.3)$ & $1196(19.7)$ & & \\
\hline & 25 - 34 Years & $7790(75.1)$ & $2576(24.9)$ & & \\
\hline & $>=35$ Years & $780(71.4)$ & $313(28.6)$ & & \\
\hline \multirow[t]{2}{*}{ Residence } & Rural & $8572(80.5)$ & $2074(19.5)$ & 202.91 & 0.001 \\
\hline & Urban & $5202(71.4)$ & $2086(28.6)$ & & \\
\hline \multirow[t]{4}{*}{ Wealth Index } & First Quartile & $3059(87)$ & $458(13)$ & 401.62 & 0.001 \\
\hline & Second Quartile & $3575(80.2)$ & $880(19.8)$ & & \\
\hline & Third Quartile & $3578(73.6)$ & $1284(26.4)$ & & \\
\hline & Fourth Quartile & $3558(69.8)$ & $1538(30.2)$ & & \\
\hline \multirow[t]{2}{*}{ Caste } & ST/SC & $5857(82.7)$ & $1226(17.3)$ & 231.6 & 0.001 \\
\hline & Others & $7194(73)$ & $2701(27)$ & & \\
\hline \multirow[t]{4}{*}{ Age at first delivery } & $<=19$ Years & $4387(84.9)$ & $783(15.1)$ & 522.76 & 0.001 \\
\hline & 20 - 24 Years & $7053(77.2)$ & $2084(22.8)$ & & \\
\hline & 25 - 34 Years & $2286(64.8)$ & $1243(35.2)$ & & \\
\hline & $>=35$ Years & $44(46.8)$ & $50(53.2)$ & & \\
\hline \multirow[t]{2}{*}{ Maternal education } & Any Schooling & $11,496(75)$ & $3832(25)$ & 192.22 & 0.001 \\
\hline & No Schooling & $2276(87.4)$ & $328(12.6)$ & & \\
\hline
\end{tabular}


Table 3 Pregnancy and delivery related factors based on type of delivery

\begin{tabular}{|c|c|c|c|c|c|}
\hline \multirow{2}{*}{$\begin{array}{l}\text { Variables } \\
\text { Antenatal care related }\end{array}$} & \multirow[t]{2}{*}{ Categories } & \multirow{2}{*}{$\begin{array}{l}\text { Normal } \\
N(\%)\end{array}$} & Caesarean & \multirow[t]{2}{*}{ Chi-Square } & \multirow[t]{2}{*}{ P-Value } \\
\hline & & & N (\%) & & \\
\hline \multirow[t]{2}{*}{$4+\mathrm{ANC}$} & Yes & $8236(73.1)$ & $3035(26.9)$ & 131.01 & 0.001 \\
\hline & No & $3413(82)$ & $749(18)$ & & \\
\hline \multirow[t]{2}{*}{ Received abdomen check BP Blood Test and Urine Test at least once } & Yes & $12,106(75.6)$ & $3913(24.4)$ & 127.63 & 0.001 \\
\hline & No & $1659(87.1)$ & $245(12.9)$ & & \\
\hline \multirow[t]{2}{*}{ USG done } & Yes & $9099(73)$ & $3360(27)$ & 325.87 & 0.001 \\
\hline & No & $4666(85.4)$ & $798(14.6)$ & & \\
\hline \multirow[t]{3}{*}{ Main place of ANC } & Public & $8163(83.3)$ & $1641(16.7)$ & 732.03 & 0.001 \\
\hline & Private & $4319(64.9)$ & $2335(35.1)$ & & \\
\hline & Home & $156(80.4)$ & 38 (19.6) & & \\
\hline \multicolumn{6}{|l|}{ Complications during pregnancy } \\
\hline \multirow[t]{2}{*}{ Pallor/ weakness/ giddiness } & Yes & $1515(75.4)$ & $495(24.6)$ & 2.61 & 0.106 \\
\hline & No & $12,258(77)$ & $3664(23)$ & & \\
\hline \multirow[t]{2}{*}{ Weak or no movement of foetus } & Yes & $273(72.4)$ & $104(27.6)$ & 4.17 & 0.041 \\
\hline & No & $13,500(76.9)$ & $4055(23.1)$ & & \\
\hline \multirow[t]{2}{*}{ Abnormal position of fetus } & Yes & $179(73.4)$ & $65(26.6)$ & 1.65 & 0.199 \\
\hline & No & $13,594(76.9)$ & $4094(23.1)$ & & \\
\hline \multirow[t]{2}{*}{ High Blood Pressure } & Yes & $527(64.9)$ & $285(35.1)$ & 67.67 & 0.001 \\
\hline & No & $13,246(77.4)$ & $3874(22.6)$ & & \\
\hline \multirow[t]{2}{*}{ Bleeding } & Yes & $143(73.3)$ & $52(26.7)$ & 1.34 & 0.248 \\
\hline & No & $13,630(76.8)$ & $4107(23.2)$ & & \\
\hline \multicolumn{6}{|l|}{ Delivery complications } \\
\hline \multirow[t]{2}{*}{ Convulsion } & Yes & $370(61.7)$ & $230(38.3)$ & 79.77 & 0.001 \\
\hline & No & $13,400(77.3)$ & $3930(22.7)$ & & \\
\hline \multirow[t]{2}{*}{ Excessive bleeding } & Yes & $718(76.5)$ & $221(23.5)$ & 0.06 & 0.803 \\
\hline & No & $13,052(76.8)$ & 3939 (23.2) & & \\
\hline \multirow[t]{2}{*}{ Prolonged labour } & Yes & $1085(73.3)$ & $396(26.7)$ & 11.34 & 0.001 \\
\hline & No & $12,685(77.1)$ & $3764(22.9)$ & & \\
\hline \multirow[t]{2}{*}{ Breach presentation } & Yes & $243(55.9)$ & $192(44.1)$ & 109.67 & 0.001 \\
\hline & No & $13,527(77.3)$ & 3968 (22.7) & & \\
\hline \multirow[t]{2}{*}{ Obstructed labour } & Yes & $1350(75.5)$ & $439(24.5)$ & 2.01 & 0.158 \\
\hline & No & $12,420(76.9)$ & $3721(23.1)$ & & \\
\hline \multirow[t]{2}{*}{ Place of delivery } & Private & $4380(62.1)$ & 2674(37.9) & 1413 & 0.001 \\
\hline & Public & 9394(86.3) & $1486(13.7)$ & & \\
\hline
\end{tabular}

Data missing: four or more antenatal care visits for 2501; Received abdomen check BP Blood Test and Urine Test at least once for 11; USG at least once for 11; Main place for 1282; Pallor/ weakness/ giddiness for 2; Weak or no movement of foetus for 2; Abnormal position of fetus for 2; High Blood Pressure for 2; Bleeding for 2; convulsion for 4; Prolonged labour for 4; Breach presentation for 4; Obstructed labour for 4

\section{Multiple logistic regression (refer Table 4)}

Table 4 shows the results of the predictor associated with caesarean section births. Particularly the sociodemographic and maternal related variables viz., residence, wealth index quartile and mothers age at first delivery are found to be statistically significant $(P$-value $<0.05)$. The odds of CS births were higher for women who belonged to urban areas (OR 1.15, 95\% CI; 1.00-1.35). The Mothers' first pregnancy at aged more than 35 years had 5.51 times more likely to have CS delivery than those were younger (age $<19$ years) at their first pregnancy (OR 5.51; 95\% CI 1.85-16.40). The women who belong to richer wealth index quartile is having more risk of CS delivery as compared to poor wealth index quartile (OR 1.19, 95\% CI; 1.01-1.57).

The predictors like more than 4 ANC check-up, ultrasound diagnosis, high BP, Excessive bleeding, breach presentation and obstructed labour were significantly 
Table 4 Association of socio-demographic, maternal, pregnancy and delivery related variables with Cesarean section deliveries using multiple logistic regression

\begin{tabular}{|c|c|c|c|c|}
\hline \multirow[t]{2}{*}{ Variables } & \multirow[t]{2}{*}{ Categories } & \multirow{2}{*}{$\begin{array}{l}\text { Total } \\
N=17,934 \text { ( } \% \text { of total) }\end{array}$} & \multicolumn{2}{|l|}{ Delivered by $\mathrm{C}$ section } \\
\hline & & & $n=4160(\%$ of $N)$ & Odds ratio $(95 \% \mathrm{Cl})$ \\
\hline \multicolumn{5}{|l|}{ Socio-demographic and maternal } \\
\hline \multirow[t]{4}{*}{ Age of Mother } & $<=19$ Years & $405(2.26)$ & $75(1.80)$ & $1.38(0.76-2.50)$ \\
\hline & $20-24$ Years & $6070(33.85)$ & $1196(28.75)$ & $1.19(0.97-1.45)$ \\
\hline & $>=35$ Years & $1093(6.09)$ & $313(7.52)$ & $1.2(0.81-1.76)$ \\
\hline & $25-34$ Years & $10,366(57.8)$ & $2576(61.92)$ & 1 \\
\hline \multirow[t]{2}{*}{ Residence } & Urban & $7288(40.64)$ & $2086(50.14)$ & $1.15(1.00-1.35)$ \\
\hline & Rural & $10,646(59.36)$ & $2074(49.86)$ & 1 \\
\hline \multirow[t]{4}{*}{ Wealth index } & Fourth & $3517(19.62)$ & $1538(36.97)$ & $1.19(1.01-1.57)$ \\
\hline & Third & $4455(24.85)$ & $1284(30.87)$ & $1.08(0.83-1.42)$ \\
\hline & Second & $4862(27.12)$ & $880(21.15)$ & $1.32(1.01-1.73)$ \\
\hline & First quartile & $5096(28.42)$ & $458(11.01)$ & 1 \\
\hline \multirow[t]{2}{*}{ Caste } & Others & $9895(55.17)$ & $2701(64.93)$ & $1.07(0.90-1.26)$ \\
\hline & ST/SC & $7083(39.49)$ & $1226(29.47)$ & 1 \\
\hline \multirow[t]{2}{*}{ Maternal education } & Any Schooling & $15,328(85.47)$ & $3832(92.12)$ & $1.01(0.74-1.36)$ \\
\hline & No Schooling & $2604(14.52)$ & $328(7.88)$ & 1 \\
\hline \multirow[t]{4}{*}{ Age at first delivery } & $>=35$ Years & $94(0.52)$ & $50(1.20)$ & $5.51(1.85-16.40)$ \\
\hline & $25-34$ Years & $3529(19.68)$ & $1243(29.88)$ & $2.49(1.87-3.32)$ \\
\hline & $20-24$ Years & $9137(50.95)$ & $2084(50.10)$ & $1.43(1.15-1.77)$ \\
\hline & $<=19$ Years & $5170(28.83)$ & $783(18.82)$ & 1 \\
\hline \multicolumn{5}{|l|}{ Antenatal care related } \\
\hline \multirow[t]{2}{*}{$4+$ ANC } & Yes & $11,271(62.85)$ & $3035(72.96)$ & $1.23(1.00-1.49)$ \\
\hline & No & $4162(23.21)$ & $749(18)$ & 1 \\
\hline \multirow{2}{*}{$\begin{array}{l}\text { Received abdomen check + BP check+ Blood Test + Urine } \\
\text { Test at least once }\end{array}$} & No & $1904(10.62)$ & $245(5.89)$ & $1.28(0.68-2.39)$ \\
\hline & Yes & 16,019 (89.32) & $3913(94.06)$ & 1 \\
\hline \multirow[t]{2}{*}{ USG done } & Yes & $12,459(69.47)$ & $3360(80.77)$ & $1.37(1.09-1.74)$ \\
\hline & No & $5464(30.47)$ & 798 (19.18) & 1 \\
\hline \multicolumn{5}{|l|}{ Complications during pregnancy } \\
\hline \multirow[t]{2}{*}{ Weak or no movement of foetus } & Yes & $377(2.1)$ & $104(2.5)$ & $1.01(0.74-1.36)$ \\
\hline & No & $17,555(97.89)$ & $4055(97.48)$ & 1 \\
\hline \multirow[t]{2}{*}{ Abnormal position of fetus } & Yes & $244(1.36)$ & $65(1.56)$ & $1.11(0.75-1.66)$ \\
\hline & No & $17,688(98.63)$ & $4094(98.41)$ & 1 \\
\hline \multirow[t]{2}{*}{ High BP } & Yes & $812(4.53)$ & $285(6.85)$ & $1.32(1.06-1.65)$ \\
\hline & No & $17,120(95.46)$ & 3874 (93.13) & 1 \\
\hline \multirow[t]{2}{*}{ Bleeding } & Yes & $195(1.09)$ & $52(26.67)$ & $1.24(0.83-1.87)$ \\
\hline & No & $17,737(98.9)$ & $4107(23.15)$ & 1 \\
\hline \multicolumn{5}{|l|}{ Delivery complications } \\
\hline \multirow[t]{2}{*}{ Convulsion } & Yes & $600(3.35)$ & $230(5.53)$ & $1.15(0.84-1.58)$ \\
\hline & No & 17,330 (96.63) & $3930(94.47)$ & 1 \\
\hline \multirow[t]{2}{*}{ Excessive bleeding } & Yes & 16,991 (94.74) & 3939 (94.69) & $1.55(1.17-2.04)$ \\
\hline & No & $939(5.24)$ & $221(5.31)$ & 1 \\
\hline \multirow[t]{2}{*}{ Prolonged labour } & Yes & 16,449 (91.72) & $3764(90.48)$ & $1.05(0.83-1.35)$ \\
\hline & No & $1481(8.26)$ & $396(9.52)$ & 1 \\
\hline
\end{tabular}


Table 4 Association of socio-demographic, maternal, pregnancy and delivery related variables with Cesarean section deliveries using multiple logistic regression (Continued)

\begin{tabular}{|c|c|c|c|c|}
\hline \multirow[t]{2}{*}{ Variables } & \multirow[t]{2}{*}{ Categories } & \multirow{2}{*}{$\begin{array}{l}\text { Total } \\
N=17,934 \text { (\% of total) }\end{array}$} & \multicolumn{2}{|c|}{ Delivered by $\mathrm{C}$ section } \\
\hline & & & $n=4160(\%$ of $\mathrm{N})$ & Odds ratio $(95 \% \mathrm{Cl}$ \\
\hline \multirow[t]{2}{*}{ Obstructed labour } & Yes & $16,141(90)$ & $3721(89.45)$ & $1.41(1.11-1.78)$ \\
\hline & No & 1789 (9.98) & 439 (10.55) & 1 \\
\hline \multirow[t]{2}{*}{ Breach presentation } & Yes & $435(2.43)$ & $192(4.62)$ & $2.37(1.63-3.43)$ \\
\hline & No & $17,495(97.55)$ & 3968 (95.38) & \\
\hline \multicolumn{5}{|l|}{ Place of delivery } \\
\hline \multirow[t]{2}{*}{ Place of Delivery } & Private & 7054 (39.33) & $2674(64.28)$ & $3.79(3.06-4.72)$ \\
\hline & Public & $10,880(60.67)$ & $1486(35.72)$ & 1 \\
\hline
\end{tabular}

associated with CS deliveries $(P$-value $<0.05)$. There is an increase in CS births with increase in the number of ANC visits. The women who had more than 4 ANC visit had 1.23 times more likely of CS delivery as compared to those who did not make any ANC visit. Complaint of high BP during pregnancy had significantly higher odds of CS births (OR 1.32; 95\% CI 1.06-1.65). The history of delivery complication especially, breach presentation (OR 2.37; 95\% CI 1.63-3.43), obstructed labour (OR 1.41 95\% CI 1.11-1.78) and excessive bleeding during delivery (OR 1.55; 95\% CI 1.17-2.04) had higher odds of CS Births. Also, delivery at a private sector health facility had 3.79 times higher odds of CS births (OR 3.79, 95\% CI 3.06-4.72) as compared to delivery at public sector health facility.

\section{Discussion}

Promoting Institutional deliveries is an important intervention of Government of India to decrease maternal morbidity and mortality. Findings show that although higher proportion of woman deliver at public sector, CS births are more in private sector health facilities. India has observed a sharp rise in institutional deliveries (Fig. 2), from $47 \%$ (DLHS 3, 2007-08) to $81.1 \%$ in current study (DLHS 4, 2011-12). This sharp increase after launch of the Janani Suraksha Yojana (JSY) and Janani Shishu Suraksha Karyakram (JSSK) schemes could be attributed to large extent to these programme being able to increase institutional births and hence decrease home deliveries [13]. Interestingly, earlier higher proportion of institutional deliveries took place in private sector whereas present study shows public sector is now bigger contributor to institutional births. Result also shows of all those delivered in private sector nearly $38 \%$ delivered by CS as compared to only $14 \%$ in public sector. Various studies have shown that there are multiple factors which influence a woman's decision to deliver by cesarean section [14]. For profit making some private sector providers may perform unwanted CS deliveries, while woman themselves can also opt for CS delivery due to fear of pain or they believe CS deliveries are safer [15-19]. In current study, CS rates in private health facilities rates are much greater than the WHO recommended maximum limit of $15 \%$ for CS births [3, 20]. Other studies have also confirmed that there is greater prevalence of CS births in private sector health facilities as compared to public sector health facilities [21-25]. Though there has been a growing demand to revisit these rates, still these rates being selectively high in private sector is area of concern. Flagship program of Government of India. "Pradhan Mantri Surakshit Matritva Abhiyan" (PMSMA) can be utilised so as to reduce service provider induced increased CS rate of private sector.

Significantly higher proportion of woman with age more than 35 years and less than 19 years were associated with increased proportion of cesarean section $(p$ value $<0.001)$. Others studies have also shown that greater maternal age as an important factor associated with cesarean births because other medical conditions like hypertension, diabetes being more prevalent at higher age group [26, 27].

More cesarean section births took place in urban woman as compared to the ones who resided in rural areas. More accessibility to medical intervention in urban areas, presence of more health facilities and insurances in urban areas can be probable reasons [28].

Wealthier woman, belonging to higher caste group and having some schooling and more likely to deliver by cesarean section $(p$ value $<0.001)$. Cesarean section seems to be a choice method for woman who can afford it rather than being a procedure for safe delivery when medically indicated $[29,30]$. Woman with lower socioeconomic status might cannot afford or do not have access to health facilities which are equipped to perform cesarean delivery. Other studies on CS births in developing countries have also supported this finding [31].

The finding of higher cesarean rates amongst mothers whose first delivery is after age of 35 years is matter of concern, since this contributes to increased further CS deliveries, considering that history of CS delivery is a relative indication for $\mathrm{CS}$ in subsequent delivery [32, 33]. 


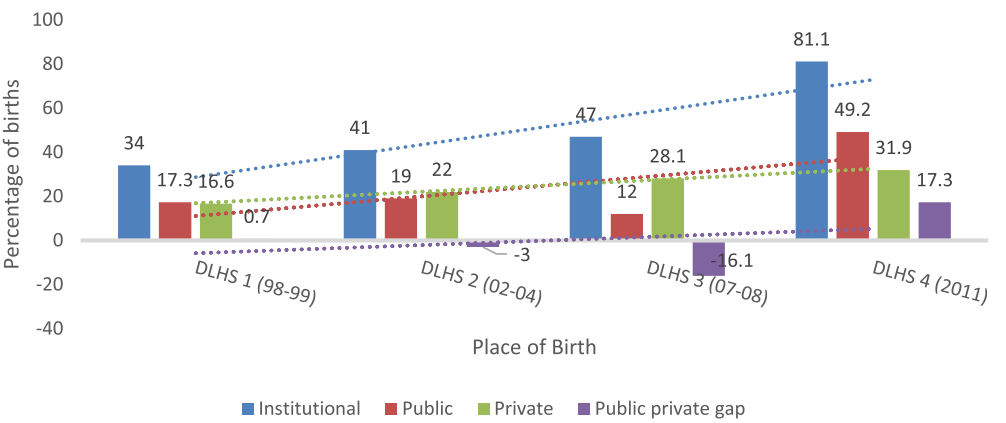

Fig. 2 Trends in Institutional deliveries in India evidence from District level Household Surveys (DLHS)

Findings shows greater number of antenatal care visits being associated with higher CS Birth rates. Women who had four or more antenatal check-ups were significantly more likely to have a CS births (OR 1.23 95\% CI 1.0-1.5). Antenatal care is the care given to pregnant woman by health care provider for safe pregnancy and child birth. Antenatal care is the ideal time to counsel and prepare pregnant woman for normal delivery (if there are no medical indications for CS), since this is the time she can interact with her care giver and plan safe delivery [19, 34]. Other studies have also shown this finding, as greater number of ANC visits allows more interaction between the care provider and pregnant woman, which might influence her to provider induced CS delivery [35, 36]. This finding has programmatic implications, ANC visit can be an opportunity to increase institutional deliveries and counsel mother regarding indications of cesarean section and risk involved $[16,19]$.

Ultrasound imaging done at least once during current pregnancy was significantly associated with higher risk of CS births. Ultrasound imaging is an essential component of antenatal care services. Also recommended by WHO for safe pregnancy and foetal monitoring [35, 36]. It helps to assess foetal growth, congenital anomalies or maternal complications if any at a very early stage so that the detected condition can be managed at the earliest $[37,38]$.

Study shows higher risk of cesarean section in case mother had complications of high blood pressure during pregnancy. Antenatal screening for high blood pressure and timely management of such mothers can bring down unwanted CS procedures. As expected, the chance of CS is higher among those who have experienced complications during delivery (excessive bleeding, obstructed labour, breach presentation). Literature also supports this finding as these complications may lead to higher risk to both mother and baby hence cesarean section needed as live saving procedure [4, 39].

\section{Conclusions}

The caesarean section is a globally recognised maternal health-care indicator. Unnecessary caesarean sections also pulls resources away from other services in overloaded and weak health systems. In India, CS rates are high in private sector health facilities, though their share in total deliveries is much lesser as compared to public sector health facilities. Hence there is need for strengthening of existing public health facilities especially, emergency obstetric care services so that if medically indicated live saving surgical procedure can be performed in public sector itself rather than drifting woman towards profit driven private sector health facilities. The government of India need to take measures to ensure that caesarean sections are performed based upon medical indications. Appropriate mechanism and specific opportunities for awareness generation and provider education, focused upon populations which are likely to prefer cesarean section, should be developed. Appropriate monitoring and accountability systems should be developed at both national and state levels in India.

\section{Key messages}

- Though higher proportions of institutional deliveries take place at public sector health facilities, Cesarean Section births are nearly three times higher in private sector health facilities.

- Non-medical determinants of Cesarean Section like place of delivery, household wealth index, residence, age of mother at first delivery, number of ANC can be looked upon in order to keep check on unwanted CS births.

- Antenatal Care can be utilised as an opportune time to explain the indication and hazards associated with CS birth.

\section{Abbreviations}

AHS: Annual Health Survey; ANC: Antenatal care; BP: Blood pressure; BP: Blood pressure; C I: Confidence interval; CS: Cesarean section: DLHS: District level household survey; JSSK: Janani Shishu Suraksha 
Karyakram; JSY: Janani Suraksha Yojana; OR: Odds ratio; PMSMA: Pradhan Mantri Surakshit Matritva Abhiyan; RCH: Reproductive child health; UT: Union Territories

\section{Acknowledgements}

The contribution of Dr. Chandrakant Lahariya in the critical review of the earlier version of the manuscript is highly appreciated.

\section{Availability of data and materials}

The datasets generated and/or analysed during the current study are available in the (IIPS, Mumbai) repository, (accessed from http:// www.iipsindia.ac.in/)

\section{Authors' contributions}

PS did the design, review of relevant literature and statistical analysis.GH and PKS contributed to the analysis, its interpretation. PS wrote the first draft of the manuscript. GH and PKS contributed on revisions of the manuscript, and all authors approved the final version.

\section{Ethics approval and consent to participate}

The DLHS-4 was collected by the International Institute for Population Sciences, Mumbai on behalf of the Ministry of Health and Family Welfare, Government of India. All data were de-identified. The de-identified version of the DLHS-4 data is publicly available upon formal request for access to the Director of India's Institute of Population Sciences. As no patient could be identified or contacted, no ethics approval was required by individual researchers to undertake this study (Please refer page no- 36 of the document Nationa ethical guidelines for biomedical and health research involving human participants link to the document- http://www.icmr.nic.in/guidelines/ ICMR_Ethical_Guidelines_2017.pdf).

\section{Competing interests}

The authors declare that they have no competing interests.

\section{Publisher's Note}

Springer Nature remains neutral with regard to jurisdictional claims in published maps and institutional affiliations.

\section{Author details}

${ }^{1}$ Nalanda Medical College, Patna, India. ${ }^{2}$ Public Health Specialist, Lucknow, India. ${ }^{3}$ Department of Statistics, Utkal University, Bhubaneswar, India.

\section{Received: 25 August 2017 Accepted: 1 May 2018}

\section{Published online: 10 May 2018}

\section{References}

1. Souza J, Gulmezoglu A, Lumbiganon P, et al. Cesarean section without medical indications is associated with an increased risk of adverse shortterm maternal outcomes: the 2004-2008 WHO global survey on maternal and perinatal health. BMC Med. 2010;8:71.

2. World Health Organization. WHO Statement on Cesarean Section Rates, 2015, Available from: http://apps.who.int/iris/bitstream/10665/161442/1/ WHO_RHR_15.02_eng.pdf. [Last Accessed 17 Aug 2017].

3. World Health Organization. Appropriate technology for birth. Lancet. 1985;2: 436-7.

4. Neuman M, Alcock G, Azad K, Kuddus A, Osrin D, More NS, Nair N, Tripathy P, Sikorski C, Saville N, Sen A. Prevalence and determinants of cesarean section in private and public health facilities in underserved south Asian communities: cross-sectional analysis of data from Bangladesh, India and Nepal. BMJ Open. 2014;4(12):e005982.

5. Ronsmans $C$, De Brouwere $V$, Dubourg D, et al. Measuring the need for lifesaving obstetric surgery in developing countries. BJOG. 2004;111:1027-30.

6. Betrán AP, Ye J, Moller AB, Zhang J, Gülmezoglu AM, Torloni MR. The increasing trend in cesarean section rates: global, regional and national estimates: 1990-2014. PLoS One. 2016;11(2):e0148343.

7. District level household \& facility survey (DLHS-3) [Internet]. Mumbai: International Institute for Population Sciences. Available from: http://rchiips. org/PRCH-3.html [Last accessed 17 Jan 2017].

8. District level household \& facility survey (DLHS-4) [Internet]. Mumbai: International Institute for Population Sciences. Available from: http://rchiips. org/DLHS-4.html. Html [Last accessed 17 Jan 2017].
9. Yoshioka-Maeda K, Ota E, Ganchimeg T, Kuroda M, Mori R. Cesarean section by maternal age group among singleton deliveries and primiparous Japanese women: a secondary analysis of the WHO global survey on maternal and perinatal health. BMC Pregnancy Childbirth. 2016;16(1):39.

10. Feng $X L, X u L$, Guo Y, Ronsmans $C$. Factors influencing rising cesarean section rates in China between 1988 and 2008. Bull World Health Organ. 2012;90(1):30-39A

11. Behague DP, Victora CG, Barros FC. Consumer demand for cesarean sections in Brazil: informed decision making, patient choice, or social inequality? A population based birth cohort study linking ethnographic and epidemiological methods. BMJ. 2002;324(7343):942

12. Oliveira RR, Melo EC, Novaes ES, Ferracioli PL, Mathias TA. Factors associated to cesarean delivery in public and private health care systems. Revista da Escola de Enfermagem da USP. 2016;50(5):733-40.

13. Randive B, Diwan V, De Costa A. India's conditional cash transfer Programme (the JSY) to promote institutional birth: is there an association between institutional birth proportion and maternal mortality? Baradaran HR, ed. PLoS One. 2013;8(6):e67452.

14. Loke AY, Davies L, Li S. Factors influencing the decision that women make on their mode of delivery: the health belief model. BMC Health Serv Res. 2015;15:274.

15. Potter JE, Berquo E, Perpétuo $\mathbb{H O}_{\mathrm{O}}$, et al. Unwanted cesarean sections among public and private patients in Brazil: prospective study. BMJ. 2001; 323(7322):1155-8

16. Sufang G, Padmadas SS, Fengmin Z, Brown JJ, Stones RW. Delivery settings and cesarean section rates in China. Bull World Health Organ. 2007:85(10):755-62

17. Lo JC. Patients' attitudes vs. physicians' determination: implications for cesarean sections. Soc Sci Med. 2003;57:91-6.

18. McCourt $\mathrm{C}$, Weaver J, Statham $\mathrm{H}$, et al. Elective cesarean section and decision making: a critical review of the literature. Birth. 2007;34:65-79.

19. Kamal SMM. Preference for institutional delivery and cesarean sections in Bangladesh. J Health Popul Nutr. 2013;31(1):96-109.

20. Chaillet N, Dubé $E$, Dugas $M$, et al. Identifying barriers and facilitators towards implementing guidelines to reduce cesarean section rates in Quebec. Bull World Health Organ. 2007:85(10):791-7.

21. Vieira GO, Fernandes $L G$, de Oliveira NF, Silva $L R$, de Oliveira Vieira $T$. Factors associated with cesarean delivery in public and private hospitals in a city of North-Eastern Brazil: a cross-sectional study. BMC Pregnancy Childbirth. 2015:15:132

22. Almeida S, Bettiol H, Barbieri MA, Silva AAM, Ribeiro VS. Significant differences in cesarean section rates between a private and a public hospital in Brazil Cad Saude Publ. 2008:24:2909-18.

23. Rebelo F, Da Rocha CMM, Cortes TR, Dutra CL, Kac G. High cesarean prevalence in a national population-based study in Brazil: the role of private practice. Acta Obstet Gynecol Scand. 2010;89:903-8.

24. Mendoza-Sassi RA, Cesar JA, Silva PR, Denardin G, Rodrigues MM. Risk factors for cesarean section by category of healthservice. Rev Saude Publ. 2010;44:80-9.

25. Beogo I, Mendez Rojas B, Gagnon M-P. Determinants and materno-fetal outcomes related to cesarean section delivery in private and public hospitals in low- and middle-income countries: a systematic review and meta-analysis protocol. Syst Rev. 2017;6:5

26. Khan MN, Islam MM, Shariff AA, Alam MM, Rahman MM. Socio-demographic predictors and average annual rates of cesarean section in Bangladesh between 2004 and 2014. PLoS One. 2017:12(5):e0177579.

27. Lin H-C, Sheen T-C, Tang C-H, Kao S. Association between maternal age and the likelihood of a cesarean section: a population-based multivariate logistic regression analysis. Acta Obstet Gynecol Scand. 2004;83:1178-83.

28. Khanal V, Karkee R, Lee AH, Binns CW. Adverse obstetric symptoms and rural-urban difference in cesarean delivery in Rupandehi district, western Nepal: a cohort study. Reprod Health. 2016;13:17.

29. Cavallaro FL, Cresswell JA, França GV, Victora CG, Barros AJ, Ronsmans C. Trends in cesarean delivery by country and wealth quintile: cross-sectional surveys in southern Asia and sub-Saharan Africa. Bull World Health Organ. 2013;91(12):914-22D

30. Ronsmans C, Holtz S, Stanton C. Socioeconomic differentials in cesarean rates in developing countries: a retrospective analysis. Lancet. 2006; 368(9546):1516-23.

31. Boatin AA, Schlotheuber A, Betran AP, et al. Within country inequalities in caesarean section rates: observational study of 72 low and middle income countries. BMJ. 2018;360:k55 
32. Moraes MS, Goldenberg P. Cesarean incidence rates: an epidemic profile. Cad Saude Publ. 2001;17:509-19.

33. Horowitz BJ, Edelstein SW, Lippman L. Once a cesarean... Always a cesarean. Obstet Gynaecol Surv. 1981;36(10):592.

34. Ashimi AO, Amole TG, Aliyu LD. Knowledge and attitude of pregnant women to cesarean section in a semi-urban community in Northwest Nigeria. J West Afr Coll Surg. 2013;3(2):46.

35. Enakpene CA, Morhason-Bello IO, Marinho AO, Adedokun BO, Kalejaiye AO, Sogo K, et al. Clients' reasons for prenatal ultrasonography in Ibadan, south west of Nigeria. BMC Womens Health. 2009;9:12.

36. Motherhood S. Mother-baby package: implementing safe motherhood in countries. Geneva, Switzerland: WHO. FHE/MSM/94; 1994.

37. Bashoura H, Hafezb R, Abdulsalamc A. Syrian Women's perceptions and experiences of ultrasound screening in pregnancy: implications for antenatal policy. Reprod Health Matters. 2005;13:147-54.

38. Gammeltoft $T$, Thi $H$, Nguyen $T$. The commodification of obstetric ultrasound scanning in Hanoi, Viet Nam. Reprod Health Matters. 2007; 15:163-71.

39. Karkee R, Lee AH, Khanal V, Pokharel PK, Binns CW. Obstetric complications and cesarean delivery in Nepal. Int J Gynaecol Obstet. 2014;125:33-6.

Ready to submit your research? Choose BMC and benefit from:

- fast, convenient online submission

- thorough peer review by experienced researchers in your field

- rapid publication on acceptance

- support for research data, including large and complex data types

- gold Open Access which fosters wider collaboration and increased citations

- maximum visibility for your research: over $100 \mathrm{M}$ website views per year

At BMC, research is always in progress.

Learn more biomedcentral.com/submissions 